\title{
Three habits of highly effective signaling pathways: principles of transcriptional control by developmental cell signaling
}

\author{
Scott Barolo and James W. Posakony ${ }^{1}$ \\ Division of Biology/CDB, University of California San Diego, La Jolla, California 92093-0349, USA
}

Seven major cell-cell signaling pathways-Wnt, TGF- $\beta$, Hedgehog (Hh), receptor tyrosine kinase (RTK), nuclear receptor, Jak/STAT, and Notch-control the vast majority of cell fate decisions during the development of bilaterian animals (Gerhart 1999). Each pathway is used repeatedly during the development of a given organism, activating different subsets of target genes in different developmental contexts. These seven pathways are strikingly diverse in both their complexity and the biochemical mechanism of signal transduction, ranging from direct transcriptional regulation by the nuclear receptor proteins to the extended protein phosphorylation cascades characteristic of RTK pathways. Nevertheless, the primary consequence of signaling is the same: activation of specific target genes by signal-regulated transcription factors.

Recent work has revealed several surprising and fundamental commonalities in the transcriptional mechanisms by which these pathways control the expression of their target genes. In this review, we discuss transcriptional regulation by developmental cell signaling pathways, and suggest that three functional properties-activator insufficiency, cooperative activation, and default repression-are shared among the major pathways. Together, these three "habits" allow signaling pathways to strongly activate target genes in their proper context, while preventing their expression in all other cells. Such strict control over target gene expression explains an extraordinary feature of developmental cell signaling: the capacity of a single pathway to elicit a large variety of gene expression patterns, and hence to control the specification of a large variety of cell fates.

\section{Signaling flips a switch}

All major developmental signaling pathways function at least in part by regulating the transcription of specific nuclear target genes in response to the binding of a sig-

${ }^{1}$ Corresponding author.

E-MAIL jposakony@ucsd.edu; FAX (858) 534-0566.

Article and publication are at http://www.genesdev.org/cgi/doi/10.1101/ gad.976502. naling ligand to the pathway's receptor. The transcriptional control function of each pathway is carried out by one or more signal-regulated transcription factors, which bind to specific signaling pathway response elements (SPREs) in the promoters or enhancers of target genes. Over the last few years, an unexpected theme has emerged: Several of these developmental control pathways have been found to use transcriptional switch mechanisms, whereby target genes are activated in the presence of signaling, but repressed in its absence (Fig. 1). We use the term default repression to refer to the transcriptional repression of target genes in the absence of signaling. A particularly exciting finding in the case of the Notch, Wnt, Hh, and nuclear receptor pathways is that default repression and signal-dependent activation of target genes are both mediated not only by the same SPREs but, in fact, by the same transcription factors$\mathrm{Su}(\mathrm{H}) / \mathrm{CBF} 1$ in the Notch pathway, Lef/Tcf proteins in the Wnt pathway, Ci/Gli in the Hh pathway, and nuclear receptors themselves. The fundamentally different mechanisms by which these four pathways convert SPRE-binding transcription factors from repressors to activators (diagrammed in simplified form in Fig. 1) suggest that each signaling pathway has independently evolved a transcriptional switch. Others of the major signaling systems, including the TGF- $\beta$ and RTK-type pathways, appear to extend the known prevalence of this switch mechanism by making use of yet another strategy for repression via their SPREs, to be discussed below in this review.

Thus, a remarkable generalization emerges: Of the major signaling pathways that control cell fate in bilaterians (and possibly in all metazoans), most, and perhaps all, act by switching their target genes from a state of transcriptional repression to one of activation, often using the very same signal-regulated transcription factor and the same binding sites (SPREs) to do so. Although the term switch implies that target genes in an individual signalresponsive cell are converted from repression to activation by a signaling event, this has not been directly shown in vivo. However, the existence of the switch is strongly supported by a substantial body of evidence (described below) that (1) the same SPREs can mediate re- 

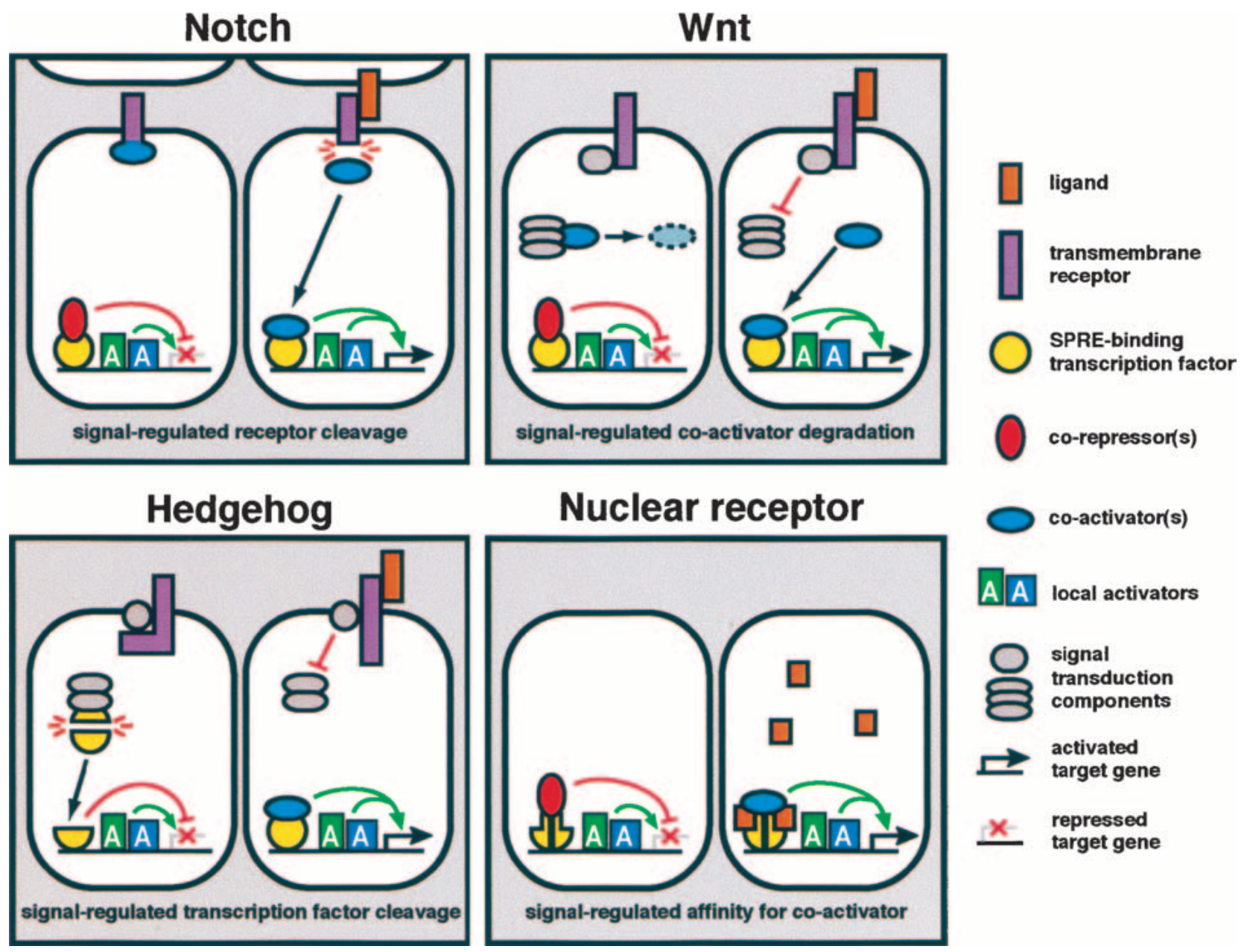

transcription factor

co-repressor(s)

co-activator(s)

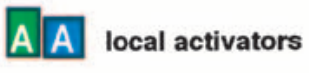

signal

transduction

components

activated

target gene

repressed

target gene

Figure 1. Major developmental signaling pathways use different mechanisms to switch from transcriptional repression to activation of target genes. Signal-regulated transcription factors for the Notch, Wnt, Hh, and nuclear receptor signaling pathways bind signaling pathway response elements (SPREs) and function as transcriptional repressors in the absence of signaling (default repression), but act as activators in response to ligand. Signal transduction mechanisms and mechanisms of transcriptional switching are depicted in simplified form. See text for discussion.

pression and activation in different cells of the same tissue, depending on the state of signaling in those cells; and (2) a transcriptional switch can be thrown experimentally in normally nonresponsive cells by ectopically activating the signaling pathway in those cells.

Default transcriptional repression via SPREs is clearly effective for keeping target genes turned off where there is no signal, but it raises the question of why it has evolved independently to become part of the regulatory mechanism underlying the operation of diverse signaling pathways. In other words, what is the selective advantage of default repression? Why isn't the absence of pathway activation sufficient to keep target genes turned off? Recent advances in understanding the specificity of gene activation by signaling pathways offer, we think, important insight into the answers to these questions. There is growing evidence that signal-regulated transcription factors share two other functional characteristics, activator insufficiency and cooperative activation, which, together with default repression, may explain signaling pathways' ability to maintain strict control of target gene expression.

\section{Habit \#1: activator insufficiency}

"If the prolactin, growth hormone, and possibly TSH genes require the same factor ... for their activation, then restrictive mechanisms, whether repression or a requirement for additional interactive factors, must account for their differential expression. .."

Nelson et al. (1988)

"How might the siamois promoter become unresponsive to Wnt signals, even when these are presented in the form of activated Tcf? One can imagine two classes of models. On one hand, promoter activation might require additional inputs...Alternatively, loss of Wnt responsiveness could result from repression. .."

Darken and Wilson (2001) 
Signaling pathway activity is generally insufficient to activate target genes

A critical, but perhaps not fully appreciated, property of developmental signaling systems is the selective transcriptional responsiveness of target genes to pathway activity. The Notch system, which is used to control a diverse array of cell fate specification events during the development of a single organism, offers an instructive example. No single Notch signaling event activates every Notch target gene; conversely, no single known target gene is activated by all Notch signaling events. In Drosophila, a substantial number of genes have been identified that are directly activated by Suppressor of Hairless, $\mathrm{Su}(\mathrm{H})$, the key signal-regulated transcription factor at the terminus of the Notch pathway, in response to Notch signaling activity. These include at least 10 genes in the Enhancer of split complex, as well as vestigial, single-minded, and Su(H) itself (Bailey and Posakony 1995; Lecourtois and Schweisguth 1995; Kim et al. 1996; Nellesen et al. 1999; Barolo et al. 2000; Lai et al. 2000; Morel and Schweisguth 2000). Yet these genes are expressed in remarkably diverse and often nonoverlapping subsets of Notch-responsive cells throughout development, in both embryonic and postembryonic tissues, and no two expression patterns are identical, even when reporter genes that reflect only transcriptional responses are considered. Moreover, in each setting, the subset of target genes that are activated by Notch signaling in turn has specific, crucial roles to play in the subsequent development of the Notch-responsive cells in that setting. Thus, single-minded, which encodes a bHLH-PAS transcription factor, is activated by Notch signaling in two rows of cells in the ventrolateral ectoderm of the fly embryo that will adopt highly specialized midline neuronal and glial fates; single-minded function is essential for all steps of midline cell development (Nambu et al. 1991). Su(H), in contrast, is (auto)activated by Notch signaling in only one cell type throughout development: the socket cells of external sensory bristles, where it is essential for the differentiation and physiological function of these organs (Barolo et al. 2000). Despite the presence of eight high-affinity $\mathrm{Su}(\mathrm{H})$ binding sites in the $\mathrm{Su}(\mathrm{H})$ socket cell enhancer, Notch signaling does not activate $\mathrm{Su}(H)$ in midline cells; nor does it activate singleminded in socket cells, despite the presence of five highaffinity $\mathrm{Su}(\mathrm{H})$ sites in the single-minded midline regulatory region.

This example illustrates a fundamental principle: The capacity of a signaling pathway to control the specification of multiple distinct cell fates is directly dependent on its capacity to activate different, though perhaps overlapping, subsets of its target genes in different developmental contexts. It is therefore critical that the activation of a given signaling pathway in a cell at physiological levels be insufficient to cause the transcriptional activation of all of its targets. To use a term from embryology, the transcriptional responses of individual target genes to signaling activity are restricted to specific zones of competence.
Because in general each target gene's response to signaling pathway activity is unique, the mechanisms that have evolved to limit the activation of targets to their proper developmental contexts must operate at the level of individual promoters. The possible mechanisms fall into two classes: active repression of target promoters/ enhancers in all inappropriate signaling contexts, and inability of signal-regulated transcription factors to activate transcription in any but the correct contexts. Both models require the presence of specific cis-regulatory elements in signal-regulated enhancers, binding either transcriptional repressors to restrict gene expression, or additional activators to facilitate expression, respectively. A direct experimental approach to discriminating these possibilities is to delete specific sequences in signal-regulated enhancers and promoters, and observe the effects on reporter gene expression in vivo. The active repression model predicts that signal-regulated enhancers can be converted into promiscuous reporters of signaling activity by knocking out repressor binding sites flanking SPREs. Conversely, the signal insufficiency model predicts that no mutation will create a strongly and promiscuously activated enhancer, but, rather, that sequences flanking SPREs are required for robust activation in the proper pattern.

This experiment has been performed on many signalregulated enhancers, including those activated by Notch, TGF- $\beta$, Wnt, nuclear receptor, Jak/STAT, Hh, and RTK signaling, with the consistent result that cis-regulatory sequences besides SPREs are required for proper target gene expression (e.g., Danesch et al. 1987; Schule et al. 1988; Singson et al. 1994; Giese et al. 1995; Rothenberg and Ward 1996; Pearce et al. 1998; Szuts et al. 1998; Hepker et al. 1999; Barolo et al. 2000; Certel et al. 2000; Flores et al. 2000; Halfon et al. 2000; Ramana et al. 2000; $\mathrm{Xu}$ et al. 2000; Affolter et al. 2001; Knirr and Frasch 2001). For example, a wing margin enhancer of the Drosophila gene vestigial that is directly activated by Dpp/ TGF- $\beta$ signaling via Mad also requires binding by the locally expressed activator Drifter for its function (Certel et al. 2000). The insufficiency of SPREs to activate transcription in vivo is perhaps most dramatically illustrated by the Drosophila even-skipped muscle and heart enhancer, which is directly activated by the Wnt, Dpp/ TGF- $\beta$, and RTK pathways (via dTCF, Mad, and Ets binding sites, respectively). Even in cells in which all three pathways are active, this enhancer is silent unless it is also bound by two mesodermally expressed activators, Twist and Tinman (Halfon et al. 2000).

No enhancer has been converted into a universal reporter of signaling pathway activity by eliminating known repressor-binding sites. This does not mean that repression is not a critical factor in regulating specific transcription; on the contrary, repression is as important as activation for generating precise patterns of developmental gene expression. Our point here is specific to the control of signal-activated target genes: Repression does not generally account for the fact that signaling pathways drive differential target gene expression in different signaling contexts. Rather, additional positively acting 
cis-regulatory sequences in signal-regulated genes (besides SPREs) are crucial for conferring the competence to be activated by signal-regulated transcription factors in a specific developmental setting.

\section{SPREs alone are poor reporters of signaling activity in Vivo}

A simple, but artificial, test of the sufficiency of a signalregulated transcription factor is the in vivo expression pattern of an artificial construct in which minimal SPREs, removed from their normal context of flanking DNA, are placed upstream of a reporter gene. Response elements for the Notch, Hh, TGF- $\beta$, RTK, Wnt, and nuclear receptor pathways have been tested for sufficiency in this manner (Antoniewski et al. 1996; Eresh et al. 1997; Riese et al. 1997; Xu et al. 1998; Hepker et al. 1999; Barolo et al. 2000; Furriols and Bray 2001; Guss et al. 2001; Koide et al. 2001; Martin et al. 2001). In general, these reporter constructs are expressed in very weak and restricted patterns, or not at all, in vivo. For example, multimerized $\mathrm{Su}(\mathrm{H})$ binding sites (i.e., Notch response elements) fail to drive significant reporter gene expression in Notch-responding cells in transgenic Drosophila (Fig. 2A; Guss et al. 2001). The vertebrate $\mathrm{Su}(\mathrm{H})$ ortholog CBF1 has been tested for sufficiency in transgenic mice, with similar results: A GFP reporter construct containing eight CBF1 binding sites (Hsieh et al. 1996) is not activated in Notch-responsive thymocytes in vivo (S.M. Lehar and M.J. Bevan, pers. comm.). It is worth pondering the significance of these negative results. Acting through binding sites in endogenous enhancer modules, signal-regulated transcription factors make very substantial contributions to the activation of their target genes. That even multiple high-affinity binding sites for such factors should generally prove insufficient to activate detectable reporter gene expression in vivo is certainly noteworthy.
Transgenic constructs derived from the TOPFLASH promoter constitute a possible exception to this rule. TOPFLASH, a reporter construct used in cell culture transfection assays, contains multiple Lef/Tcf binding sites (Wnt response elements) upstream of a $c$-fos promoter (Korinek et al. 1997). In both mice and zebrafish, reporter transgenes containing the TOPFLASH promoter are expressed in certain Wnt-responsive cell types (DasGupta and Fuchs 1999; Dorsky et al. 2002). However, a more minimal reporter construct in transgenic flies, containing Lef/Tcf binding sites comparable to those in TOPFLASH, is not expressed in any embryonic cells, even under conditions of ubiquitous expression of the Wingless ligand (Riese et al. 1997). More significantly, the fact that natural Lef/Tcf-activated enhancers require additional activators for proper expression (Carlsson et al. 1993; Giese et al. 1995; Brannon et al. 1997; Eresh et al. 1997; McKendry et al. 1997; Szuts et al. 1998; Hecht and Kemler 2000; Nishita et al. 2000; Darken and Wilson 2001) indicates that Lef/Tcf binding sites are insufficient for normal target gene activation in their native cis-regulatory contexts.

Overall, the preponderance of evidence thus far indicates that SPREs alone, particularly as they are configured in the native context of an enhancer module, are insufficient to drive target gene expression in response to cell signaling in vivo. We refer to this property of signalregulated transcription in vivo as activator insufficiency, the first of the three habits (Fig. 3).

\section{SPREs: insufficient in animals, but sufficient in cultured cells}

The results of the transgenic animal experiments described above contrast sharply with observations made in experiments with cultured cells, in which multimerized SPREs, such as binding sites for Smads, $\mathrm{Su}(\mathrm{H}) / \mathrm{CBF} 1$, STATs, Lef/Tcfs, nuclear receptors, and Ets proteins are

Figure 2. Insufficiency of the signal-regulated activator $\mathrm{Su}(\mathrm{H})$ (Notch pathway) versus local activator sufficiency. (A) Wing imaginal disc from a Drosophila larva carrying a lac $Z$ transgene driven by four tandem, high-affinity $\mathrm{Su}(\mathrm{H})$ binding sites upstream of a minimal promoter $\left[4 \mathrm{xSu}(\mathrm{H})_{-}\right.$ lac $Z$ ]. Reporter gene expression is assayed by $\beta$-galactosidase activity staining. Four $\mathrm{Su}(\mathrm{H})$ sites are insufficient to activate detectable reporter expression in the many Notch-responsive cells in the wing disc, which include sensory organ proneural clusters (inset, marked by expression of a
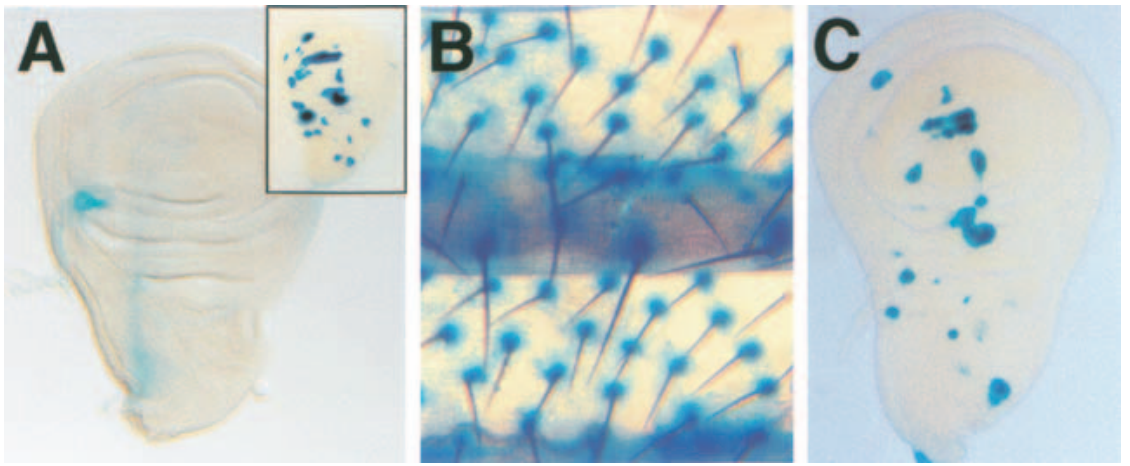
lacZ reporter gene driven by the promoter and proximal upstream region of Enhancer of split $m 4$, a direct target of regulation by Su(H); Bailey and Posakony 1995). (B) 4xSu(H)-lacZ expression in mechanosensory bristles of the adult abdomen. Four Su(H) sites are sufficient to drive reporter gene expression in adult socket cells, a context in which transcriptional activation by $\mathrm{Su}(\mathrm{H})$ is independent of Notch signaling (Barolo et al. 2000). (C) Partial sufficiency of proneural bHLH proteins as local activators expressed in proneural clusters, sites of active Notch signaling for the specification of sensory organ precursor cells (see inset to A). Shown is the pattern of expression of a lac $Z$ reporter construct in which a minimal promoter is driven by four high-affinity E-box binding sites for proneural protein complexes (Van Doren et al. 1991; Singson et al. 1994; Singson 1995). Proneural bHLH activators are sufficient to elicit transcription of the reporter gene in a substantial subset of proneural cluster cells in the wing imaginal disc (cf. $A_{\text {; }}$ Singson 1995). 


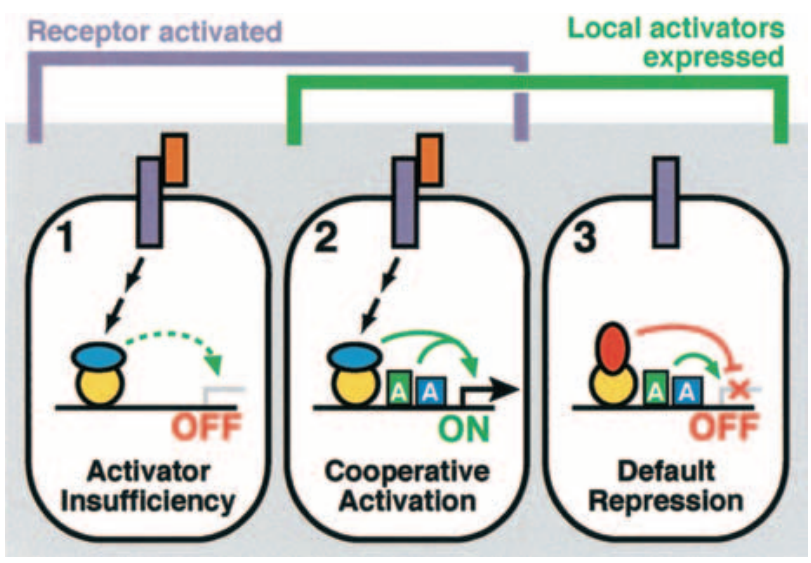

Figure 3. Specificity of signaling pathway target gene expression depends on three common principles of transcriptional control. Symbols are drawn as in Figure 1. (1) We propose that a general property of activator insufficiency-the inability of a signal-regulated transcription factor alone to strongly activate gene expression in vivo in the presence of active signalingprevents signaling pathways from activating all of their target genes during each signaling event. (2) Only by acting cooperatively with tissue- or cell-type-specific local activators can signal-regulated activators drive high levels of target gene expression. (3) Local activators, unlike signal-regulated activators, can be partially or fully sufficient to activate target genes. A general property of default repression, mediated by signal-regulated transcription factors in the absence of signaling, limits target gene expression to cells that both express the appropriate local activators and receive signaling. These interconnected transcriptional control principles place tight restrictions on the expression of signaling pathway target genes, while allowing robust target gene expression in appropriate contexts. Such strict specificity of target gene transcription permits a single signaling pathway to activate different subsets of target genes in different contexts throughout development.

usually found to drive high levels of gene expression in response to signal (e.g., Galang et al. 1994; Furukawa et al. 1995; Korinek et al. 1997; Zawel et al. 1998; Kwon et al. 2000; Ghbeish et al. 2001). Perhaps the difference is that cultured cell lines may be subjected to much higher levels of signaling, and/or much higher transcription factor concentrations, than any cell experiences during normal development. This view is consistent with evidence that artificially increased levels of signaling sometimes, but not always, ectopically activate multimerized SPRE constructs in vivo (e.g., Eresh et al. 1997; Furriols and

${ }^{1}$ Our observation that multimerized $\mathrm{Su}(\mathrm{H})$ binding sites (Notch response elements) are insufficient to activate reporter gene expression in proneural clusters and other settings, but are sufficient in adult socket cells (Fig. 2B; Barolo et al. 2000), is consistent with this idea. Adult socket cells are a site of Notch signaling-independent $\mathrm{Su}(\mathrm{H})$-mediated activation, and the activity of an SPRE-only construct in these cells shows that $\mathrm{Su}(\mathrm{H})$, when it does not rely on Notch for activation (i.e., in nonsignaling contexts), can function sufficiently as an activator.

${ }^{2}$ Our definition of local activators includes the tissue- or compartmentspecific factors encoded by selector genes (Garcia-Bellido 1975). However, in principle, the expression or activity of local activators can be limited to one or two cells.
Bray 2001). Alternatively, the inhibitory effects of chromatin structure on transcription, from which transfected constructs are likely exempt, may explain this discrepancy. Whatever the reason, transient transfection experiments in cultured cells evidently do not faithfully reflect the activity of SPREs during normal development.

\section{How is the activation function of signal-regulated transcription factors made insufficient?}

Activator insufficiency need not be an inherent property of signal-regulated transcription factors, or of the activation complexes with which they interact. ${ }^{1}$ There are many mechanisms by which signaling pathways might limit the activation potential of the transcription factors they regulate, because anything that limits the flux of signal through the pathway at any level could in principle limit the final level of an activated transcription factor. Thus, parameters as diverse as amount of ligand and/or receptor, efficiency of transduction, and affinities of protein-protein or protein-DNA interactions in the pathway could evolve so as to lead to net insufficiency of the signaling pathway to activate target genes indiscriminately.

Particularly worthy of mention are negative feedback mechanisms, which may be signal-regulated or constitutive, and include degradation of transcription factors, induction of corepressor expression, stimulation of SPRE-binding repressors, inhibition of kinase cascades by protein phosphatases, nonproductive sequestration of ligand, and destabilization of enhanceosomes by coactivators (e.g., Martin-Blanco 1998; Zhu et al. 1999). In fact, several lines of evidence (for review, see Tansey 2001) suggest that negative feedback may be intrinsic to activation by eukaryotic transcription factors.

Finally, as we have mentioned, many SPREs mediate transcriptional repression, as well as activation, of the genes they regulate. We suggest that SPRE-mediated repression is potentially a major contributor to activator insufficiency, a point which is discussed in detail below.

Activator insufficiency helps explain why signaling pathways don't indiscriminately activate all of their target genes during every signaling event (Fig. 3). Nevertheless, signaling pathways can drive high levels of SPREdependent target gene expression in their proper contexts. How is robust but spatially restricted target gene activation achieved?

\section{Habit \#2: cooperative activation}

The general answer is combinatorial transcriptional regulation (Fig. 3). Signal-activated promoters and enhancers typically contain not only SPREs, but also binding sites for one or more transcriptional activators whose activity is signal-independent, and whose expression or activity is restricted to specific territories or groups of cells. We call such factors local activators. ${ }^{2}$ Synergy or cooperativity in transcriptional activation makes combinations of signal-activated factors and local activators sufficient to activate target genes (Fig. 3). Genes activated by all seven of the developmental signaling path- 
ways discussed in this review have been shown to require input from signal-independent activators (e.g., Schule et al. 1988; Bailey and Posakony 1995; Giese et al. 1995; Rothenberg and Ward 1996; Pearce et al. 1998; Hepker et al. 1999; Certel et al. 2000; Flores et al. 2000; Halfon et al. 2000; Li et al. 2000; Ramana et al. 2000; Xu et al. 2000; Affolter et al. 2001; Knirr and Frasch 2001). Although local activators have not been identified for all signal-regulated developmental enhancers, no such enhancer has been found to rely solely on SPREs for its activity. Studies of Notch pathway target genes in Drosophila illustrate clearly how signal-regulated transcriptional activation by $\mathrm{Su}(\mathrm{H})$ is integrated with different local activator proteins to generate a variety of distinct expression patterns: (1) Synergistic activation requiring both $\mathrm{Su}(\mathrm{H})$ binding sites (Notch response elements) and sites for the proneural bHLH activators of the achaetescute complex is necessary for high levels of Enhancer of split complex gene expression in proneural clusters in the ectoderm (Singson et al. 1994; Bailey and Posakony 1995; Nellesen et al. 1999; Cooper et al. 2000). (2) The single-minded gene, activated by the ventral determinants Dorsal and Twist as well as by $\mathrm{Su}(\mathrm{H})$, is expressed in Notch-responsive mesectodermal cells in the embryo (Morel and Schweisguth 2000). (3) The wing margin (boundary) enhancer of vestigial requires direct inputs from both $\mathrm{Su}(\mathrm{H})$ and the wing selector proteins Vestigial and Scalloped (Halder et al. 1998). (4) The Su(H) socket cell-specific enhancer requires auto-activation by a Notch $/ \mathrm{Su}(\mathrm{H})$ complex as well as an unidentified enhancer-binding factor(s), the activity of which is limited to the socket and shaft cells of the mechanosensory bristle (Barolo et al. 2000). (5) Notch-mediated activation of D-Pax2 in cone cells of the eye depends on direct activation by $\mathrm{Su}(\mathrm{H})$, the RTK-activated Ets protein PointedP2 (PntP2), and the local activator Lozenge (Flores et al. 2000). (6) Recent experiments show that $\mathrm{Su}(\mathrm{H})$ and Twist binding sites in the Enhancer of split m6 upstream region are essential to drive expression specifically in Notch-responsive, Twist-positive adult muscle precursor cells (R. Bodner and J.W. Posakony, unpubl.). These examples illustrate the versatility with which the same signal-regulated transcription factor can function combinatorially with a diverse set of local activators to generate diverse expression specificities. ${ }^{3}$

The capacity of combinations of signal-regulated factors and local activators to drive robust activation of target promoters (in contrast to signal-regulated factors alone) results from the superadditive effects of these combined inputs on the rate of transcription. Such synergistic interactions are not, of course, a special property of the transcriptional activators that work through signal-regulated enhancers. The general ability of binding sites for multiple transcriptional activators, or multiple binding sites for the same activator, to produce manyfold greater than additive effects on gene expression has been well recognized since the 1980s (e.g., Zenke et al. 1986; Lin et al. 1988; Nelson et al. 1988; Schule et al. 1988). This second habit of transcriptional regulation by developmental signaling pathways, referred to in this re- view as cooperative activation (Fig. 3), may involve synergy at the level of activator binding to DNA, or at the level of activator interactions with coactivators, chromatin remodeling factors, and/or components of the basal transcription complex (for review, see Herschlag and Johnson 1993; Carey 1998; Courey 2001).

As described above, and in some recent reports (e.g., Halder et al. 1998; Guss et al. 2001), combinatorial control of gene transcription would seem to require only two inputs for full expression in the proper pattern. Real enhancers, however, are generally more complex, for a number of reasons. First, the required input from local activators may, in fact, consist of a combination of multiple local activators whose expression or activity overlaps. For example, in addition to $\mathrm{Su}(\mathrm{H})$, the singleminded mesectodermal enhancer requires activation by both Dorsal and Twist, active in overlapping territories in the ventral part of the embryo, for full expression (Kasai et al. 1998; Morel and Schweisguth 2000). Activation by other signaling pathways may also be required (e.g., Halfon et al. 2000). Certain well-characterized signalregulated enhancers have been shown to require binding by between four and eight different factors for full expression (for review, see Rothenberg and Ward 1996; Carey 1998). Second, ubiquitous DNA-binding factors, whether transcription factors or architectural proteins such as chromatin-remodeling factors or enhancer-promoter looping proteins, may be required for enhancer activity (e.g., Rothenberg and Ward 1996; Small et al. 1996; Massagué and Wotton 2000; Struhl 2001).

Cooperative/synergistic interactions between signalregulated transcription factors and local activators represent an extremely effective solution to the problem of specificity of target gene activation by signaling pathways. Only the appropriate target genes-those with binding sites for both the signal-regulated factor and the local activator(s)-are activated in the appropriate cells-those that both express the local activator(s) and have activated receptor (Fig. 3).

However, a potentially very serious drawback to this otherwise elegant solution to the specificity problem is that local activators are often partially sufficient to activate target genes, even in the absence of input via SPREs (Fig. 2C). This weak sufficiency may be a property

\footnotetext{
${ }^{3}$ It should be noted that the transcriptional insufficiency of SPREs is compatible with the possibility of a target gene being activated in every signal-responsive cell. This requires only that the particular local activator(s) that cooperate with the signal-regulated activator to drive the gene in question must be expressed in every signaling context, or perhaps ubiquitously. Although universally responsive direct target genes are rare, one possible example is the Drosophila patched gene, a negativefeedback regulator of the $\mathrm{Hh}$ pathway, which is directly activated by $\mathrm{Ci}$ in response to most or all Hh signaling events (Alexandre et al. 1996). The simplest way to model such an expression pattern would be to partner Ci-binding sites with sites for a ubiquitously expressed activator. Ci should cooperate with the ubiquitous factor to activate transcription in all Hh-responding cells, and repress expression in all other cells. We have made just such an artificial enhancer, which gives a patched-like expression pattern in imaginal disks of transgenic flies (data not shown). Although no positive inputs to the patched promoter besides Ci have yet been identified, it is interesting to note that patched is expressed ubiquitously in early embryos, and is later repressed in non-Hh-responsive cells (Hidalgo and Ingham 1990).
} 
either of a single local activator or, more generally, of an ensemble of such activators (perhaps including ubiquitous factors) that serve a signal-regulated enhancer module. In any case, many signal-regulated enhancers retain some activity and, in fact, are often expressed in a broader (if weaker) pattern when their SPREs are mutated (Barolo et al. 2000; Müller and Basler 2000). For example, mutating the dTCF binding sites (Wnt response elements) in a mesodermal enhancer of Drosophila evenskipped weakens its expression in Wnt-responsive cells, but also expands its expression to mesodermal cells outside the normal pattern of even-skipped expression (Knirr et al. 1999).

Implicit in the modern understanding of the selector gene concept (Garcia-Bellido 1975) is the notion that selector genes, or local activators, are typically expressed in more cells than those that will ultimately adopt a particular selector gene-dependent fate (Davidson 2001). Sometimes this means expression in a broad territory in a tissue (e.g., vestigial in the wing pouch region of the wing imaginal disc); sometimes in smaller zones (e.g., proneural genes in proneural clusters); sometimes in only two cells (e.g., in sister cells in a lineage). This is an essential strategy in the progressive definition of cell fate on finer and finer scales during development (Davidson 2001). The consequence for the present discussion is that the weak sufficiency of local activators is a very real threat to signaling pathways' control of their target genes. One or more cells in a given context-those that express the local activator(s) but do not normally respond to the signal-are at risk of inappropriately activating pathway target genes in a signal-independent manner.

\section{Habit \#3: default repression}

\section{Default repression keeps local activators under control}

How, then, to preserve the tremendous advantage of specificity that cooperative activation offers, while at the same time avoiding the serious problem presented by the weak sufficiency of local activators? The very elegant solution, arrived at evidently independently by most or all of the major developmental signaling pathways, is default repression-transcriptional repression mediated by SPREs in the absence of signaling. This strategy ensures that "at risk" target genes (those with the appropriate binding sites) are kept in an "off" state despite the presence of the cognate local activator(s), until and unless sufficient signal is transduced through the receptor.

Default repression is a vital component of the signalregulated transcriptional switches described above in this review. We imagine at least four possible types of transcriptional switches controlling the activity of SPRE-containing enhancer modules, each using a different regulatory mechanism, but all dependent on default repression (Fig. 4A).

Type I Default repression and signal-dependent activation are mediated by the same SPRE-binding transcrip- tion factor. Signaling converts this factor from a repressor to an activator, thus simultaneously derepressing and activating transcription. This is the most common form of transcriptional switch identified to date.

Type II This switch uses separate, dedicated repressor and activator proteins, both binding to the same or overlapping enhancer sequences. In the presence of signaling, SPRE-bound repressors are displaced by activators. In principle, the activities of repressors, activators, or both could be the signal-regulated elements in this type of switch.

Type III Dedicated activators and repressors recognize separate DNA binding sites. Signal-regulated activators stimulate target promoters by direct activation (overcoming the effect of the repressor) and/or derepression (directly antagonizing the repressor's activity).

Type IV This is the simplest possible form of default repression-based switch, using no SPRE-binding activator. Signaling acts solely by derepression, depending on local or ubiquitous activators to drive target gene expression. Because such a regulatory mechanism lacks a positive signal-dependent input, its status as a true switch may be debatable, but its effects on target gene transcription are indistinguishable from those of the other types of switch (Fig. 4A).

Four major pathways-Notch, Hh, Wnt, and nuclear receptor-use a Type I transcriptional switch, in which the same signal-regulated transcription factor mediates default repression in the absence of signaling, but acts as an activator in signal-responding cells (see Fig. 1; Kao et al. 1998; Méthot and Basler 1999; Roose and Clevers 1999; Aranda and Pascual 2001). Transcription factors regulated by TGF- $\beta$ and RTK/Ras/MAPK signaling have also been implicated in repression, and may also make use of transcriptional switch mechanisms. Evidence for default repression in these pathways will be discussed separately below. Of the seven signaling pathways under discussion here, evidence for default repression in the Jak/STAT pathway is by far the weakest. In fact, it is currently nonexistent, with the possible exception of a recent report of functional interactions between the STAT5 transcription factor and the SMRT corepressor complex (Nakajima et al. 2001). Whether this interaction mediates default repression of Jak/STAT target genes remains to be seen.

\section{Default repression in TGF- $\beta / D p p$ signaling}

Vertebrate Smad transcription factors, which transduce the TGF- $\beta$ signal, associate with two types of corepressors, TGIF and Ski/SnoN (Massagué and Wotton 2000). TGIF-Smad interactions are induced by pathway signaling, which suggests that repression mediated by TGIF is not default repression, but may instead be a negative feedback mechanism to limit the potency or duration of activation during signaling events. In fact, because the 


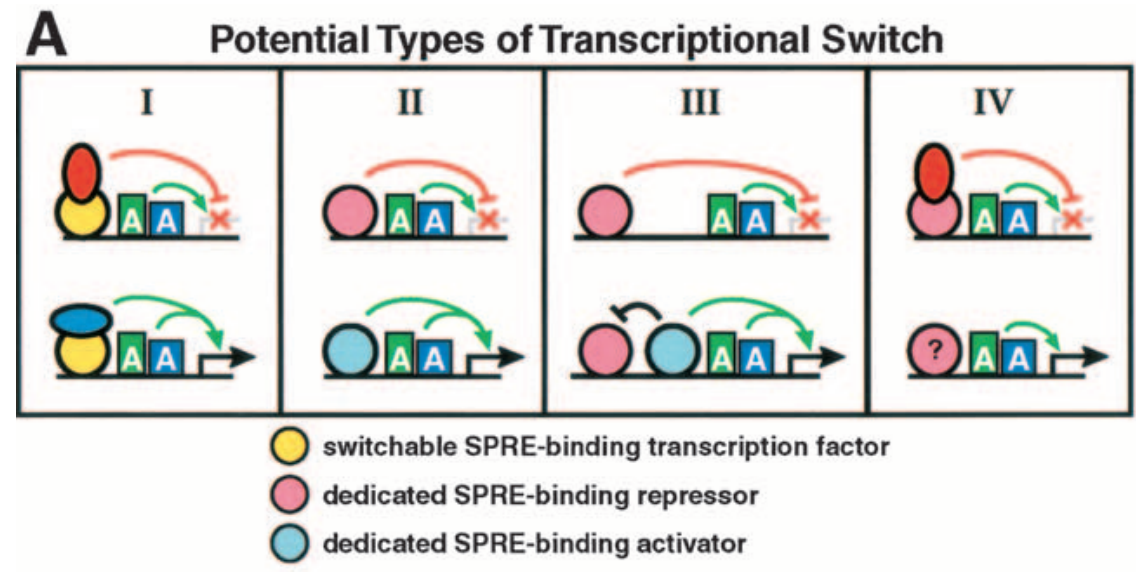

Figure 4. Proposed transcriptional switches in TGF- $\beta$ and RTK pathway signaling. $(A)$ Four possible types of transcriptional switch mediated by SPREs. Symbols are drawn as in Figure 1, except that dedicated SPRE-binding repressors and activators are drawn as pink and blue circles, respectively. See text for discussion. (B) A proposed Type II transcriptional switch in Dpp/TGF- $\beta$ signaling in Drosophila. The repressor Brinker (pink), expression of which is repressed by Dpp signaling, and Smads (blue), which are activated by signaling, bind to overlapping sites. Black circles with white $\mathrm{P}$ represent protein phosphorylation. $(C)$ Expression patterns of the Dpp ligand, the repressor Brinker (Brk), and the local activator complex Scalloped/Vestigial $(\mathrm{Sd} / \mathrm{Vg})$, relative to the anterior/posterior boundary of the wing imaginal disc. $(D)$ Regulation of two SPRE-binding Ets proteins, the repressor Yan (pink) and the activator PntP2 (blue), by RTK/Ras/MAPK signaling in a proposed Type II switch in Drosophila. (E) Derepression of terminal patterning genes by the Torso RTK in a possible Type IV transcriptional switch in Drosophila. See text for discussion. These four categories of transcriptional switch, which are not mutually exclusive, have not all been definitively shown to exist, nor do they necessarily cover all possible switchbased signaling mechanisms.

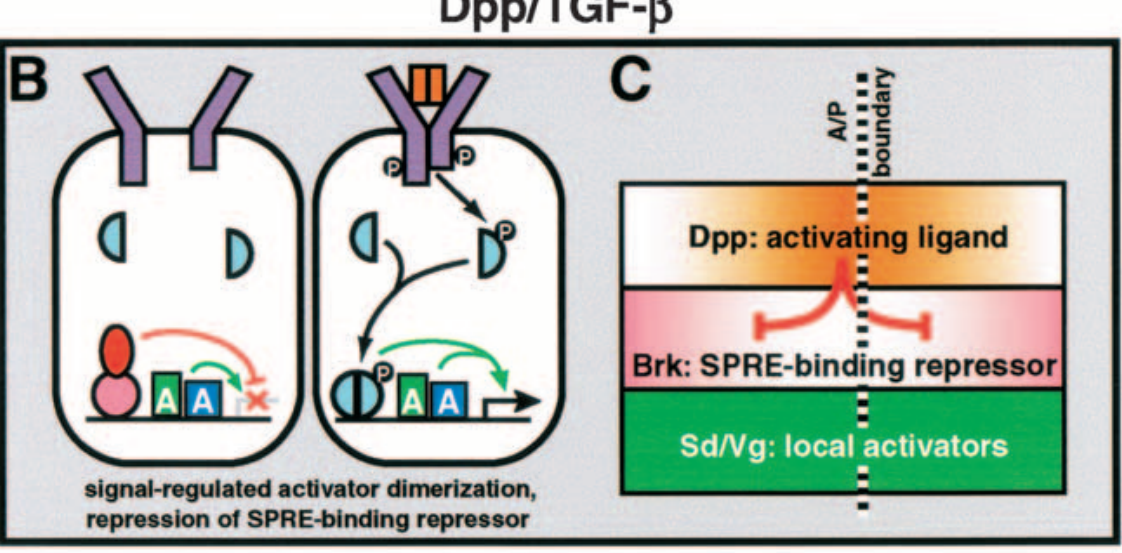

\section{RTK/Ras/MAPK}

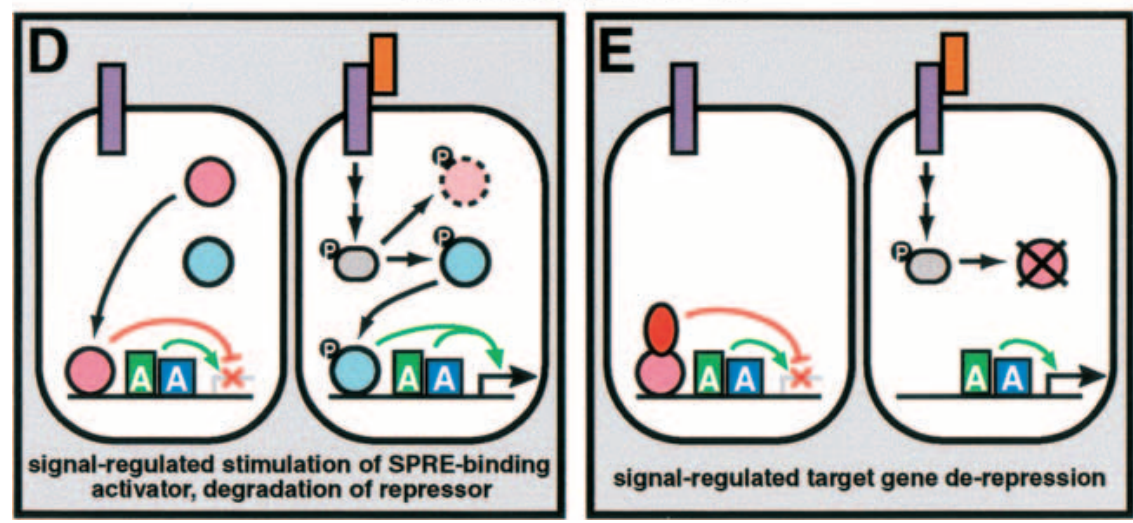

nuclear import of Smads seems to depend on signaling, a simple default repression mechanism mediated directly by Smads would appear to be ruled out. However, the constitutive interaction between Smads and the corepressors Ski and SnoN, which is disrupted by TGF- $\beta$ signaling, might suggest a repressive role for Smads in the absence of signaling.

Alternatively, evidence that signal-activated Smads can directly derepress target promoters /Verschueren et al. 1999) indicates that default repression and signal-induced activation of TGF- $\beta$ target genes can be mediated by separate transcription factors. Strong support for this model comes from studies of TGF- $\beta$ signaling via the Dpp pathway in Drosophila (Fig. 4; for review, see Affolter et al. 2001). The transcription factor Brinker directly represses Dpp target genes in the absence of signaling. Brinker and Drosophila Smads frequently bind to overlapping sites, and compete for interaction with DNA. An additional layer of regulation exists: Transcription of the brinker gene is inhibited (probably indirectly) by Dpp signaling (Fig. 4B,C). Thus, several Dpp target genes are subject to a Type II transcriptional switch, in 
which pathway activation results in (1) reduced expression of an SPRE-binding repressor, (2) direct derepression of pathway target genes by competitive binding of activated Smads to repressor-bound SPREs, and (3) direct activation of Dpp target promoters by Smads bound to SPREs (Fig. 4B). The negative regulation of brinker expression by Dpp signaling illustrates a significant element of regulatory versatility afforded by the use of a Type II, as compared with a Type I, switch mechanism. Because in a Type II switch default repression and signalstimulated activation are carried out by different transcription factors, mechanisms for signal-dependent negative regulation of default repressor expression are readily evolved and can be used to enhance the capacity of the signal to effect a switch from repression to activation.

\section{Default repression in RTK signaling}

RTK/Ras/MAPK signaling also appears to throw a transcriptional switch, at least in certain cases. Two Ets transcription factors, mouse Net and goldfish GETS-1, act as constitutive repressors, but are converted to direct transcriptional activators by Ras/MAPK signaling (Fig. 4D; for review, see Mavrothalassitis and Ghysdael 2000). In several developmental contexts in Drosophila, two MAPK-regulated Ets proteins, the Yan repressor and the PntP2 activator, function in what appears to be a Type II transcriptional switch (Fig. 4D). Yan and PntP2 bind to many of the same sites in RTK-activated enhancers (Flores et al. 2000; Halfon et al. 2000; Xu et al. 2000). In the absence of signaling, Yan mediates default repression of pathway target genes, whereas PntP2 is inactive. RTK/ Ras/MAPK signaling results in the phosphorylation of both transcription factors, inactivating Yan and stimulating PntP2, thus both derepressing and activating target gene expression (Brunner et al. 1994; O'Neill et al. 1994; Rebay and Rubin 1995; Gabay et al. 1996; Flores et al. 2000; Halfon et al. 2000; Xu et al. 2000; Baker et al. 2001). The vertebrate Ets repressor protein ERF, which is excluded from the nucleus in response to Ras/MAPK signaling, may serve a function analogous to that of Yan (Mavrothalassitis and Ghysdael 2000).

Patterning of the Drosophila embryonic termini depends on Ras/MAPK signaling downstream of the Torso RTK. The transcription factor Capicua represses the terminal genes tailless $(t 1 l)$ and huckebein $(h \mathrm{~kb})$; Torso signaling inactivates Capicua, thus derepressing $t 11$ and $h k b$ expression in terminal regions of the embryo (Fig. 4E; Jiménez et al. 2000 and references therein). Torso signaling also relieves Dorsal-mediated silencing of the zerknüllt (zen) and $d p p$ genes at the embryonic termini, but has very little effect on transcriptional activation (Rusch and Levine 1994). Genetic experiments suggest that the activators of terminal genes such as $t 11$ and zen may be ubiquitously expressed (Rusch and Levine 1994; Paroush et al. 1997). Given that no direct activation function has been found downstream of Torso, and activation of $t 11$ and zen in repression-deficient embryos does not require Torso signaling, it may be that Torso target genes rely on a Type IV (derepression only) switch mechanism.

\section{Common cofactors in default repression}

Default repression, then, appears to play an important and even critical role in transcriptional regulation by at least six major developmental signaling pathways. Although each pathway uses different DNA-binding transcription factors to repress target genes in the absence of signaling, non-DNA-binding corepressor proteins are often shared by multiple pathways. For example, the SMRT/N-Cor family of corepressors is recruited by factors regulated by the nuclear receptor, Notch, TGF- $\beta$, RTK, and Jak/STAT pathways (e.g., Chen and Evans 1995; Kao et al. 1998; Luo et al. 1999; Hong and Privalsky 2000; Nakajima et al. 2001). The corepressor C-terminal binding protein $(\mathrm{CtBP})$ is recruited to SPREs for the Wnt, RTK, TGF- $\beta$, and Notch pathways (e.g., Roose and Clevers 1999; Grooteclaes and Frisch 2000; Hasson et al. 2001; Morel et al. 2001; S. Barolo, T. Stone, A.G. Bang, and J.W. Posakony, in prep.). Groucho/TLE corepressors are used for default repression in the Wnt, TGF- $\beta$, and Notch pathways (Cavallo et al. 1998; Brantjes et al. 2001; Hasson et al. 2001; S. Barolo, T. Stone, A.G. Bang, and J.W. Posakony, in prep.). Such commonalities suggest a general mechanism of default repression, to be discussed below.

\section{Default repression and cell fate}

Thus far we have considered default repression in the mechanistic context of transcriptional control. But how important is it to cell fate specification? A signal-dependent binary cell fate decision between sister cells in the Drosophila adult sensory organ lineage offers an answer to this question. The socket and shaft cells of adult mechanosensory bristles arise via an asymmetric cell division in which the presumptive socket cell responds to Notch signaling, while its sister cell, the presumptive shaft cell, is rendered immune to signaling by its inheritance of Numb (Posakony 1994; Guo et al. 1996). Nevertheless, specification of the shaft cell fate depends crucially on default repression by $\mathrm{Su}(\mathrm{H})$ (Barolo et al. 2000). In the absence of Notch signaling, the Hairless protein functions as an adaptor to recruit the corepressor proteins dCtBP and Groucho to Su(H) (Morel et al. 2001; S. Barolo, T. Stone, A.G. Bang, and J.W. Posakony, in prep.). Reduction of Hairless function transforms shaft cells into socket cells (Bang et al. 1991). Thus, a shaft cell lacking default repression is at serious risk of inappropriately activating Notch pathway target genes and adopting the same cell fate as its sister, even in the absence of signal-mediated activation (Barolo et al. 2000).

\section{Functional, mechanistic, and evolutionary considerations}

Each habit contributes to both qualitative and quantitative patterning of target gene expression

All three of the principles of transcriptional control by signaling pathways discussed in this review make a vital contribution to target gene regulation, not just at the 
level of spatial and temporal patterning, but in terms of quantitative differences in gene expression levels between cells that are "on" and those that should be "off". Sharp differences in gene expression levels are essential for precise patterning events in which a given cell is meant to respond to a signal (and thus adopt a distinct fate), but its neighbor must remain unresponsive. All patterning events require precision, but contexts such as lateral inhibition, in which only a single cell out of a group takes a distinct fate, or boundary formation, in which a single row of cells is distinguished from its immediate neighbors, illustrate the need for both strict spatial accuracy in target gene activation and robust differences in gene expression between responding and nonresponding cells.

The contribution made by cooperative activation to sharp boundaries of gene expression is well understood: Compared to additive effects on transcriptional activation, it dramatically increases target gene expression in cells that have both local activator expression and activated receptor (Fig. 5A,B). This amplifies the difference in target gene expression levels, or $\Delta_{\mathrm{e}}$, between on and off cells. Activator insufficiency ensures that cells that receive a signal, but lack local activators, do not express target genes, thus increasing $\Delta_{\mathrm{e}}$ among signal-receiving cells (Fig. 5C). As we have discussed, many local activators are partially sufficient to activate signal-regulated enhancers in the absence of signaling. Default repression prevents such ectopic expression, increasing $\Delta_{\mathrm{e}}$ between cells that do and do not respond to signaling among those that express local activators (Fig. 5D). The overall result of the combined action of the three habits is a sharp on-off distinction in levels of expression of signaling pathway target genes, even from one cell to its immediate neighbors (Fig. 5D).

\section{"Broadening and weakening": telltale signs of a switch}

Mutation of SPREs within a signal-regulated enhancer, or mutation of genes encoding signal-regulated transcription factors, often has a dual effect on target gene expression: reduced expression in signal-responding cells, and expansion of gene expression into nonresponding cells (Fig. 5E; Barolo et al. 2000). This "broadening and weakening" effect is caused by the simultaneous loss of cooperative activation and default repression, both of which depend on the same SPREs in many target gene enhancers (Fig. 5E). The expansion of target gene expression is limited to cells expressing the appropriate local activators, and more specifically to cells in which local activators are sufficient to drive detectable target gene transcription in the absence of input from signal-regulated factors. Of course, if local activators are never sufficient to activate a particular target gene without cooperation from signal-regulated factors, no broadening of expression is observed when SPREs are mutated.

Recognition of the widespread occurrence of default repression has substantial predictive and interpretive value: It likely accounts for several reports of transcrip-

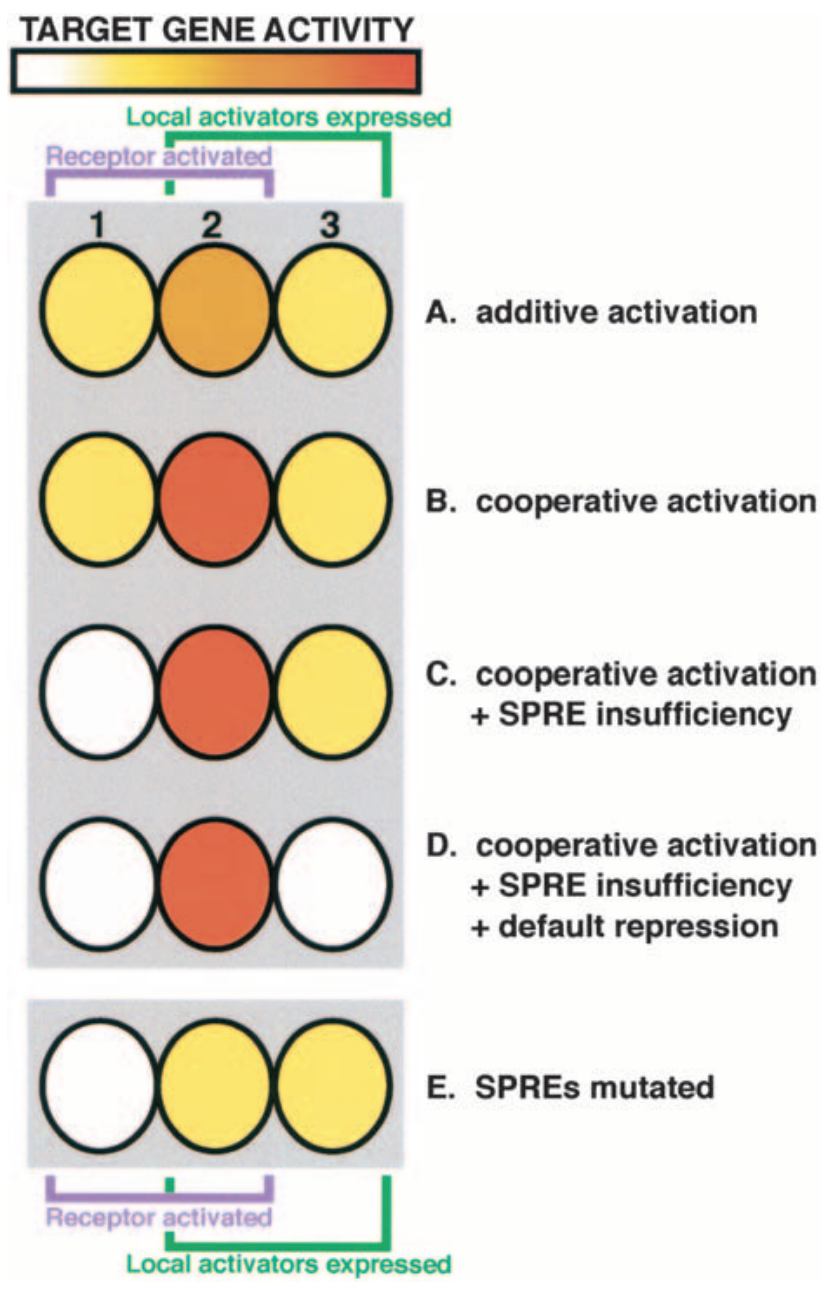

Figure 5. Activator insufficiency, cooperative activation, and default repression all help to amplify differences in target gene expression. This cartoon illustrates the contribution of the three habits to differences in target gene expression $\left(\Delta_{\mathrm{e}}\right)$ between on cells and off cells. This hypothetical example synthesizes the results of experiments discussed in this review. The color of the cell indicates the expression level of a target gene that is activated by cell signaling (via SPREs) and by local activator proteins. Of the three cells shown, cells 1 and 2 receive active cell signaling, whereas cells 2 and 3 contain local activators; only cell 2 has both. (A) Noncooperative, or additive, transcriptional activation creates a relatively small $\Delta_{\mathrm{e}}$ between cell 2 and either of the other cells. (B) Cooperative or synergistic activation greatly increases target gene expression in cell 2 , thus increasing $\Delta_{\mathrm{e}}$ (C) Insufficiency of the signal-regulated activator (acting via SPREs, hence SPRE insufficiency) ensures that target gene activation is restricted to cells expressing the appropriate local activators, further increasing $\Delta_{\mathrm{e}}$ between cells 1 and 2. (D) Default repression prevents inappropriate target gene activation by weakly sufficient local activators in the absence of signaling, thus amplifying $\Delta_{\mathrm{e}}$ between cells 2 and 3. (E) Mutating SPREs in a signal-activated enhancer (or genetically removing the function of SPRE-binding factors) often causes a broadening and weakening effect due to the simultaneous loss of default repression and cooperative activation.

tion factor-independent signaling events, because in a Type I transcriptional switch (Fig. 4A), pathway target 
genes are both deactivated and derepressed in the absence of the signal-activated transcription factor or its cognate binding sites. In Drosophila, for example, cubitus interruptus (ci) mutant embryos have a much milder segment polarity phenotype than do embryos lacking hedgehog function. This might be interpreted as evidence for a Ci-independent $\mathrm{Hh}$ pathway /Gallet et al. 2000), but the discovery of Ci-mediated default repression provides an alternative explanation: Loss of the Hh ligand, affecting only SPRE-mediated activation while leaving default repression intact, causes a more severe reduction of target gene expression than does the loss of the signal-regulated factor $\mathrm{Ci}$, which simultaneously deactivates and derepresses target genes (Méthot and Basler 2001).

Certain Notch signaling events in Drosophila have likewise been proposed to be independent of $\mathrm{Su}(\mathrm{H})$, although no other transducing transcription factor for the Notch pathway has been identified (Lecourtois and Schweisguth 1995; Matsuno et al. 1997; Wang et al. 1997; Nagel et al. 2000). Subsequently, mutating Su(H) binding sites in two Notch-activated enhancers was found to cause broadening and weakening of expression (Barolo et al. 2000; Morel and Schweisguth 2000). This and other evidence indicates that $\mathrm{Su}(\mathrm{H})$ mediates default repression as part of a transcriptional switch (Barolo et al. 2000; Morel and Schweisguth 2000; Morel et al. 2001; S. Barolo, T. Stone, A.G. Bang, and J.W. Posakony, in prep.). It is possible, then, that derepression of Notch target genes in $\mathrm{Su}(\mathrm{H})$ mutants will account for at least some reported cases of $\mathrm{Su}(\mathrm{H})$-independent Notch signaling.

\section{Signal-regulated enhancers and chromatin}

Regulation of histone acetylation is a vital component of transcriptional control (Struhl 1998). Many transcriptional activators recruit histone acetyltransferase (HAT) activity to the promoter, and it is increasingly difficult to find a repressor protein that is not implicated in histone deacetylation. Perhaps unsurprisingly, the link between chromatin and transcription applies to default repression and signal-dependent activation as well. Transcriptional activators regulated by all seven of the developmental signaling pathways under discussion here have been shown to interact with $\mathrm{CBP} / \mathrm{p} 300$ complexes and other proteins with HAT activity (Bhattacharya et al. 1996; Kamei et al. 1996; Akimaru et al. 1997; Feng et al. 1998; Janknecht et al. 1998; Yang et al. 1998; Hecht et al. 2000; Oswald et al. 2001). Conversely, SPRE-mediated default repression generally involves the recruitment of corepressors such as Groucho/TLE, CtBP, CIR, and SMRT/ N-Cor, which bind to Sin3/HDAC histone deacetylase complexes (see above). Thus, the functional consequences of the transcriptional switch seem to be mediated largely at the level of chromatin structure. As we have mentioned, the central role of chromatin regulation in transcriptional control may explain the fact that SPRE-containing constructs often behave differently in vivo and in transfected cell culture.

\section{Function and evolution of activator insufficiency}

We would like to suggest that two of the principles of transcriptional regulation by developmental signaling pathways discussed here-default repression and activator insufficiency-may not be independent. Specifically, default repression may play a crucial role in setting the threshold of pathway activity below which signaling is insufficient to activate target genes. To take a simple example, when a cell receives a signal via one of the pathways that uses a Type I switch, the signal-activated transcription factor almost certainly does not convert quantitatively from a pure default repressor to a pure activator at all binding sites on all target genes. Rather, it is the balance between the repressor and the activator forms of the factor that determines the transcriptional response of the target (Cavallo et al. 1998). We suggest that signaling pathways and signal-activated transcription factors have evolved so that the in vivo level of signal flux is insufficient to convert enough of the factor to the activator form to turn on a target gene by itself in the face of some continued repression-hence activator insufficiency. But in synergistic combination with local activators, this level of flux becomes sufficient, allowing net transcriptional activation of target genes. Similar arguments apply in the case of pathways using other types of transcriptional switch (see Fig. 4).

The notion that default repression is an essential component of activator insufficiency can be subjected to experimental test if default repression can be selectively abrogated without affecting activation. This can be difficult in the case of Type I signaling switches, in which the same signal-regulated factor mediates both default repression and signal-dependent activation. Nevertheless, Koide et al. (2001), using constructs injected into Xenopus embryos, have shown that when repression mediated by the SMRT corepressor is disrupted, the nuclear receptor RAR $\alpha$ becomes sufficient to activate reporter gene expression in the presence of ligand. Similarly, are multimerized $\mathrm{Su}(\mathrm{H})$ binding sites-insufficient in a wildtype animal (Fig. 2A)-now sufficient to direct reporter gene transcription in a Hairless mutant background? In principle, a Type II switch might afford an excellent test of SPRE sufficiency in a setting lacking default repression. Therefore, in a genetic background lacking the function of the default repressor Yan, are multimerized Ets binding sites now sufficient to activate PntP2-driven reporter gene expression in response to RTK/Ras/MAPK signaling (Fig. 4D)?

\section{Conclusion}

We end this review where we began, with the remarkable knowledge that a handful of developmental cell signaling pathways control the vast majority of patterning and cell fate specification events during bilaterian development. The highly versatile reusability of the same small set of signaling pathways depends directly on their capacity to generate a high degree of specificity in the pattern, timing, and level of expression of their diverse 
target genes. We have suggested here that developmental signaling pathways make use of three common principles of transcriptional control in order to achieve this (Fig. 3).

Activator insufficiency prevents pathway target genes from being activated by signaling indiscriminately, in inappropriate developmental contexts.

Cooperative activation by a combination of signalregulated transcription factors and local activators allows high levels of target gene expression in response to pathway signaling specifically in the appropriate contexts.

Default repression restricts the ability of otherwise weakly sufficient local activators to activate target genes in the absence of signaling.

That such very different signaling pathways as we have considered here should rely for their effectiveness on the same three transcriptional control principles is certainly significant, and suggests the unique power of this combination of strategies to solve the target genespecificity problem.

The enhancers that direct signal-responsive developmental gene expression are the context in which these three abstract principles display their real-life functional significance. It has become clear that the integrative (information-processing) capacity of transcriptional cisregulatory modules lies at the heart of developmental gene control in bilaterians (Davidson 2001). Equally important, the internal operating principles and modular organization of these cis-regulatory units are likely to be central to the generation of diversity in evolution, that is, the acquisition of novel patterning and differentiation programs, and hence the appearance of novel cell, tissue, and organ types (Davidson 2001). The three habits of activator insufficiency, cooperative activation, and default repression clearly form part of the rulebook by which novel signal-regulated cis-regulatory modules arise in evolution.

\section{Acknowledgments}

We thank Sophie M. Lehar and Michael J. Bevan for communicating unpublished results, and Richard Dorsky and Marc van de Wetering for providing further details of published experiments. Andrew Singson performed the experiment shown in Figure 2C. We thank W. McGinnis, M.G. Rosenfeld, D.N. Arnosti, L.A. Johnson, P. Towb, and N. Reeves for helpful comments on the manuscript.

\section{References}

Affolter, M., Marty, T., Vigano, M.A., and Jazwinska, A. 2001. Nuclear interpretation of Dpp signaling in Drosophila. EMBO J. 20: 3298-3305.

Akimaru, H., Chen, Y., Dai, P., Hou, D.X., Nonaka, M., Smolik, S.M., Armstrong, S., Goodman, R.H., and Ishii, S. 1997. Drosophila CBP is a co-activator of Cubitus interruptus in
Hedgehog signalling. Nature 386: 735-738.

Alexandre, C., Jacinto, A., and Ingham, P.W. 1996. Transcriptional activation of hedgehog target genes in Drosophila is mediated directly by the Cubitus Interruptus protein, a member of the GLI family of zinc finger DNA-binding proteins. Genes \& Dev. 10: 2003-2013.

Antoniewski, C., Mugat, B., Delbac, F., and Lepesant, J.A. 1996 Direct repeats bind the EcR/USP receptor and mediate ecdysteroid responses in Drosophila melanogaster. Mol. Cell. Biol. 16: 2977-2986.

Aranda, A. and Pascual, A. 2001. Nuclear hormone receptors and gene expression. Physiol. Rev. 81: 1269-1304.

Bailey, A.M. and Posakony, J.W. 1995. Suppressor of Hairless directly activates transcription of Enhancer of split Complex genes in response to Notch receptor activity. Genes \& Dev. 9: 2609-2622.

Baker, D.A., Mille-Baker, B., Wainwright, S.M., Ish-Horowicz, D., and Dibb, N.J. 2001. Mae mediates MAP kinase phosphorylation of Ets transcription factors in Drosophila. $\mathrm{Na}$ ture 411: 330-334.

Bang, A.G., Hartenstein, V., and Posakony, J.W. 1991. Hairless is required for the development of adult sensory organ precursor cells in Drosophila. Development 111: 89-104.

Barolo, S., Walker, R.G., Polyanovsky, A.D., Freschi, G., Keil, T., and Posakony, J.W. 2000. A Notch-independent activity of Suppressor of Hairless is required for normal mechanoreceptor physiology. Cell 103: 957-969.

Bhattacharya, S., Eckner, R., Grossman, S., Oldread, E., Arany, Z., D'Andrea, A., and Livingston, D.M. 1996. Cooperation of Stat 2 and $\mathrm{p} 300 / \mathrm{CBP}$ in signalling induced by interferon- $\alpha$. Nature 383: 344-347.

Brannon, M., Gomperts, M., Sumoy, L., Moon, R.T., and Kimelman, D. 1997. A $\beta$-catenin/XTcf-3 complex binds to the siamois promoter to regulate dorsal axis specification in Xenopus. Genes \& Dev. 11: 2359-2370.

Brantjes, H., Roose, J., van De Wetering, M., and Clevers, H. 2001. All Tcf HMG box transcription factors interact with Groucho-related co-repressors. Nucleic Acids Res. 29: 14101419.

Brunner, D., Ducker, K., Oellers, N., Hafen, E., Scholz, H., and Klambt, C. 1994. The ETS domain protein pointed-P2 is a target of MAP kinase in the sevenless signal transduction pathway. Nature 370: 386-389.

Carey, M. 1998. The enhanceosome and transcriptional synergy. Cell 92: 5-8.

Carlsson, P., Waterman, M.L., and Jones, K.A. 1993. The hLEF/ TCF- $1 \alpha$ HMG protein contains a context-dependent transcriptional activation domain that induces the TCR $\alpha$ enhancer in T cells. Genes \& Dev. 7: 2418-2430.

Cavallo, R.A., Cox, R.T., Moline, M.M., Roose, J., Polevoy, G.A., Clevers, H., Peifer, M., and Bejsovec, A. 1998. Drosophila Tcf and Groucho interact to repress Wingless signalling activity. Nature 395: 604-608.

Certel, K., Hudson, A., Carroll, S.B., and Johnson, W.A. 2000. Restricted patterning of vestigial expression in Drosophila wing imaginal discs requires synergistic activation by both Mad and the drifter POU domain transcription factor. Development 127: 3173-3183.

Chen, J.D. and Evans, R.M. 1995. A transcriptional co-repressor that interacts with nuclear hormone receptors. Nature 377: 454-457.

Cooper, M.T., Tyler, D.M., Furriols, M., Chalkiadaki, A., Delidakis, C., and Bray, S. 2000. Spatially restricted factors cooperate with Notch in the regulation of Enhancer of split genes. Dev. Biol. 221: 390-403.

Courey, A.J. 2001. Cooperativity in transcriptional control. 
Curr. Biol. 11: R250-R252.

Danesch, U., Gloss, B., Schmid, W., Schutz, G., Schule, R., and Renkawitz, R. 1987. Glucocorticoid induction of the rat tryptophan oxygenase gene is mediated by two widely separated glucocorticoid-responsive elements. EMBO J. 6: 625630.

Darken, R.S. and Wilson, P.A. 2001. Axis induction by wnt signaling: Target promoter responsiveness regulates competence. Dev. Biol. 234: 42-54.

DasGupta, R. and Fuchs, E. 1999. Multiple roles for activated LEF/TCF transcription complexes during hair follicle development and differentiation. Development 126: 4557-4568.

Davidson, E.H. 2001. Genomic regulatory systems-Development and evolution. Academic Press, San Diego, CA.

Dorsky, R.I., Sheldahl, L.C., and Moon, R.T. 2002. A transgenic Lef $1 / \beta$-Catenin-dependent reporter is expressed in spatially restricted domains throughout zebrafish development. Dev. Biol. 241: 229-237

Eresh, S., Riese, J., Jackson, D.B., Bohmann, D., and Bienz, M. 1997. A CREB-binding site as a target for decapentaplegic signalling during Drosophila endoderm induction. EMBO J. 16: 2014-2022.

Feng, X.H., Zhang, Y., Wu, R.Y., and Derynck, R. 1998. The tumor suppressor Smad4/DPC4 and transcriptional adaptor $\mathrm{CBP} / \mathrm{p} 300$ are coactivators for Smad3 in TGF- $\beta$-induced transcriptional activation. Genes \& Dev. 12: 2153-2163.

Flores, G.V., Duan, H., Yan, H., Nagaraj, R., Fu, W., Zou, Y., Noll, M., and Baneriee, U. 2000. Combinatorial signaling in the specification of unique cell fates. Cell 103: 75-85.

Furriols, M. and Bray, S. 2001. A model Notch response element detects Suppressor of hairless-dependent molecular switch. Curr. Biol. 11: 60-64.

Furukawa, T., Kobayakawa, Y., Tamura, K., Kimura, K., Kawaichi, M., Tanimura, T., and Honjo, T. 1995. Suppressor of Hairless, the Drosophila homologue of RBP-Jк, transactivates the neurogenic gene E(spl)m8. Ipn. J. Genet. 70: 505524.

Gabay, L., Scholz, H., Golembo, M., Klaes, A., Shilo, B.Z., and Klambt, C. 1996. EGF receptor signaling induces pointed P1 transcription and inactivates Yan protein in the Drosophila embryonic ventral ectoderm. Development 122: 3355-3362.

Galang, C.K., Der, C.J., and Hauser, C.A. 1994. Oncogenic Ras can induce transcriptional activation through a variety of promoter elements, including tandem c-Ets-2 binding sites. Oncogene 9: 2913-2921.

Gallet, A., Angelats, C., Kerridge, S., and Therond, P.P. 2000. Cubitus interruptus-independent transduction of the Hedgehog signal in Drosophila. Development 127: 5509-5522.

Garcia-Bellido, A. 1975. Genetic control of wing disc development in Drosophila. CIBA Found. Symp. 29: 161-182.

Gerhart, J. 1999. 1998 Warkany lecture: Signaling pathways in development. Teratology 60: 226-239.

Ghbeish, N., Tsai, C.C., Schubiger, M., Zhou, J.Y., Evans, R.M., and McKeown, M. 2001. The dual role of ultraspiracle, the Drosophila retinoid $\mathrm{X}$ receptor, in the ecdysone response. Proc. Natl. Acad. Sci. 98: 3867-3872.

Giese, K., Kingsley, C., Kirshner, J.R., and Grosschedl, R. 1995. Assembly and function of a TCR $\alpha$ enhancer complex is dependent on LEF-1-induced DNA bending and multiple protein-protein interactions. Genes \& Dev. 9: 995-1008.

Grooteclaes, M.L. and Frisch, S.M. 2000. Evidence for a function of $\mathrm{CtBP}$ in epithelial gene regulation and anoikis. Oncogene 19: 3823-3828.

Guo, M., Jan, L.Y., and Jan, Y.N. 1996. Control of daughter cell fates during asymmetric division: Interaction of Numb and Notch. Neuron 17: 27-41.
Guss, K.A., Nelson, C.E., Hudson, A., Kraus, M.E., and Carroll S.B. 2001. Control of a genetic regulatory network by a selector gene. Science 292: 1164-1167.

Halder, G., Polaczyk, P., Kraus, M.E., Hudson, A., Kim, J., Laughon, A., and Carroll, S. 1998. The Vestigial and Scalloped proteins act together to directly regulate wing-specific gene expression in Drosophila. Genes \& Dev. 12:39003909.

Halfon, M.S., Carmena, A., Gisselbrecht, S., Sackerson, C.M., Jimenez, F., Baylies, M.K., and Michelson, A.M. 2000. Ras pathway specificity is determined by the integration of multiple signal-activated and tissue-restricted transcription factors. Cell 103: 63-74.

Hasson, P., Muller, B., Basler, K., and Paroush, Z. 2001. Brinker requires two corepressors for maximal and versatile repression in Dpp signalling. EMBO J. 20: 5725-5736.

Hecht, A. and Kemler, R. 2000. Curbing the nuclear activities of $\beta$-catenin: Control over Wnt target gene expression. EMBO Reports 1: 24-28.

Hecht, A., Vleminckx, K., Stemmler, M.P., van Roy, F., and Kemler, R. 2000. The p300/CBP acetyltransferases function as transcriptional coactivators of $\beta$-catenin in vertebrates. EMBO I. 19: 1839-1850.

Hepker, J., Blackman, R.K., and Holmgren, R. 1999. Cubitus interruptus is necessary but not sufficient for direct activation of a wing-specific decapentaplegic enhancer. Development 126: 3669-3677.

Herschlag, D. and Johnson, F.B. 1993. Synergism in transcriptional activation: A kinetic view. Genes \& Dev. 7: 173-179.

Hidalgo, A. and Ingham, P. 1990. Cell patterning in the Drosophila segment: Spatial regulation of the segment polarity gene patched. Development 110: 291-301.

Hong, S.H. and Privalsky, M.L. 2000. The SMRT corepressor is regulated by a MEK-1 kinase pathway: Inhibition of corepressor function is associated with SMRT phosphorylation and nuclear export. Mol. Cell. Biol. 20: 6612-6625.

Hsieh, J.J., Henkel, T., Salmon, P., Robey, E., Peterson, M.G., and Hayward, S.D. 1996. Truncated mammalian Notch1 activates CBF1/RBPJк-repressed genes by a mechanism resembling that of Epstein-Barr virus EBNA2. Mol. Cell. Biol. 16: 952-959.

Janknecht, R., Wells, N.J., and Hunter, T. 1998. TGF- $\beta$-stimulated cooperation of Smad proteins with the coactivators $\mathrm{CBP} / \mathrm{p} 300$. Genes \& Dev. 12: 2114-2119.

Jiménez, G., Guichet, A., Ephrussi, A., and Casanova, J. 2000. Relief of gene repression by torso RTK signaling: Role of capicua in Drosophila terminal and dorsoventral patterning Genes \& Dev. 14: 224-231.

Kamei, Y., Xu, L., Heinzel, T., Torchia, J., Kurokawa, R., Gloss, B., Lin, S.C., Heyman, R.A., Rose, D.W., Glass, C.K., et al. 1996. A CBP integrator complex mediates transcriptional activation and AP-1 inhibition by nuclear receptors. Cell 85: 403-414.

Kao, H.Y., Ordentlich, P., Koyano-Nakagawa, N., Tang, Z., Downes, M., Kintner, C.R., Evans, R.M., and Kadesch, T. 1998. A histone deacetylase corepressor complex regulates the Notch signal transduction pathway. Genes \& Dev. 12: 2269-2277.

Kasai, Y., Stahl, S., and Crews, S. 1998. Specification of the Drosophila CNS midline cell lineage: Direct control of single-minded transcription by dorsal/ventral patterning genes. Gene Expr. 7: 171-189.

Kim, J., Sebring, A., Esch, J.J., Kraus, M.E., Vorwerk, K., Magee, J., and Carroll, S.B. 1996. Integration of positional signals and regulation of wing formation and identity by Drosophila vestigial gene. Nature 382: 133-138. 
Knirr, S. and Frasch, M. 2001. Molecular integration of inductive and mesoderm-intrinsic inputs governs even-skipped enhancer activity in a subset of pericardial and dorsal muscle progenitors. Dev. Biol. 238: 13-26.

Knirr, S., Azpiazu, N., and Frasch, M. 1999. The role of the NK-homeobox gene slouch (S59) in somatic muscle patterning. Development 126: 4525-4235.

Koide, T., Downes, M., Chandraratna, R.A., Blumberg, B., and Umesono, K. 2001. Active repression of RAR signaling is required for head formation. Genes \& Dev. 15: 2111-2121.

Korinek, V., Barker, N., Morin, P.J., van Wichen, D., de Weger, R., Kinzler, K.W., Vogelstein, B., and Clevers, H. 1997. Constitutive transcriptional activation by a $\beta$-catenin-Tcf complex in $\mathrm{APC}^{-/-}$colon carcinoma. Science 275: 1784-1787.

Kwon, E.J., Park, H.S., Kim, Y.S., Oh, E.J., Nishida, Y., Matsukage, A., Yoo, M.A., and Yamaguchi, M. 2000. Transcriptional regulation of the Drosophila raf proto-oncogene by Drosophila STAT during development and in immune response. J. Biol. Chem. 275: 19824-19830.

Lai, E.C., Bodner, R., and Posakony, J.W. 2000. The Enhancer of split Complex of Drosophila includes four Notch-regulated members of the Bearded gene family. Development 127: 3441-3455.

Lecourtois, M. and Schweisguth, F. 1995. The neurogenic Suppressor of hairless DNA-binding protein mediates the transcriptional activation of the Enhancer of split complex genes triggered by Notch signaling. Genes \& Dev. 9: 2598-2608.

Li, R., Pei, H., and Watson, D.K. 2000. Regulation of Ets function by protein-protein interactions. Oncogene 19: 65146523.

Lin, Y.S., Carey, M.F., Ptashne, M., and Green, M.R. 1988. GAL4 derivatives function alone and synergistically with mammalian activators in vitro. Cell 54: 659-664.

Luo, K., Stroschein, S.L., Wang, W., Chen, D., Martens, E., Zhou, S., and Zhou, Q. 1999. The Ski oncoprotein interacts with the Smad proteins to repress TGF- $\beta$ signaling. Genes \& Dev. 13: 2196-2206.

Martin, E.L., Consales, C., Davidson, E.H., and Arnone, M.I. 2001. Evidence for a mesodermal embryonic regulator of the sea urchin CyIla gene. Dev. Biol. 236: 46-63.

Martin-Blanco, E. 1998. Regulatory control of signal transduction during morphogenesis in Drosophila. Int. J. Dev. Biol. 42: 363-368.

Massagué, J. and Wotton, D. 2000. Transcriptional control by the TGF- $\beta /$ Smad signaling system. EMBO J. 19: 1745-1754.

Matsuno, K., Go, M.J., Sun, X., Eastman, D.S., and ArtavanisTsakonas, S. 1997. Suppressor of Hairless-independent events in Notch signaling imply novel pathway elements. Development 124: 4265-4273.

Mavrothalassitis, G. and Ghysdael, J. 2000. Proteins of the ETS family with transcriptional repressor activity. Oncogene 19: 6524-6532.

McKendry, R., Hsu, S.C., Harland, R.M., and Grosschedl, R. 1997. LEF-1/TCF proteins mediate Wnt-inducible transcription from the Xenopus nodal-related 3 promoter. Dev. Biol. 192: 420-431.

Méthot, N. and Basler, K. 1999. Hedgehog controls limb development by regulating the activities of distinct transcriptional activator and repressor forms of Cubitus interruptus. Cell 96: 819-831.

- 2001. An absolute requirement for Cubitus interruptus in Hedgehog signaling. Development 128: 733-742.

Morel, V. and Schweisguth, F. 2000. Repression by Suppressor of hairless and activation by Notch are required to define a single row of single-minded expressing cells in the Drosophila embryo. Genes \& Dev. 14: 377-388.
Morel, V., Lecourtois, M., Massiani, O., Maier, D., Preiss, A. and Schweisguth, F. 2001. Transcriptional repression by Suppressor of hairless involves the binding of a HairlessdCtBP complex in Drosophila. Curr. Biol. 11: 789-792.

Müller, B. and Basler, K. 2000. The repressor and activator forms of Cubitus interruptus control Hedgehog target genes through common generic gli-binding sites. Development 127: 2999-3007

Nagel, A.C., Maier, D., and Preiss, A. 2000. Su(H)-independent activity of Hairless during mechano-sensory organ formation in Drosophila. Mech. Dev. 94: 3-12.

Nakajima, H., Brindle, P.K., Handa, M., and Ihle, J.N. 2001. Functional interaction of STAT5 and nuclear receptor corepressor SMRT: Implications in negative regulation of STAT5-dependent transcription. EMBO J. 20: 6836-6844.

Nambu, J.R., Lewis, J.O., Wharton, K.A., Jr., and Crews, S.T. 1991. The Drosophila single-minded gene encodes a helixloop-helix protein that acts as a master regulator of CNS midline development. Cell 67: 1157-1167.

Nellesen, D.T., Lai, E.C., and Posakony, J.W. 1999. Discrete enhancer elements mediate selective responsiveness of Enhancer of split Complex genes to common transcriptional activators. Dev. Biol. 213: 33-53.

Nelson, C., Albert, V.R., Elsholtz, H.P., Lu, L.I., and Rosenfeld, M.G. 1988. Activation of cell-specific expression of rat growth hormone and prolactin genes by a common transcription factor. Science 239: 1400-1405.

Nishita, M., Hashimoto, M.K., Ogata, S., Laurent, M.N., Ueno, N., Shibuya, H., and Cho, K.W. 2000. Interaction between Wnt and TGF- $\beta$ signalling pathways during formation of Spemann's organizer. Nature 403: 781-785.

O'Neill, E.M., Rebay, I., Tjian, R., and Rubin, G.M. 1994. The activities of two Ets-related transcription factors required for Drosophila eye development are modulated by the Ras/ MAPK pathway. Cell 78: 137-147.

Oswald, F., Tauber, B., Dobner, T., Bourteele, S., Kostezka, U., Adler, G., Liptay, S., and Schmid, R.M. 2001. p300 acts as a transcriptional coactivator for mammalian Notch-1. Mol. Cell. Biol. 21: 7761-7774.

Paroush, Z., Wainwright, S.M., and Ish-Horowicz, D. 1997. Torso signalling regulates terminal patterning in Drosophila by antagonising Groucho-mediated repression. Development 124: 3827-3834.

Pearce, D., Matsui, W., Miner, J.N., and Yamamoto, K.R. 1998. Glucocorticoid receptor transcriptional activity determined by spacing of receptor and nonreceptor DNA sites. J. Biol. Chem. 273: 30081-30085.

Posakony, J.W. 1994. Nature versus nurture: Asymmetric cell divisions in Drosophila bristle development. Cell 76: 415418.

Ramana, C.V., Chatterjee-Kishore, M., Nguyen, H., and Stark, G.R. 2000. Complex roles of Stat1 in regulating gene expression. Oncogene 19: 2619-2627.

Rebay, I. and Rubin, G.M. 1995. Yan functions as a general inhibitor of differentiation and is negatively regulated by activation of the Ras1/MAPK pathway. Cell 81: 857-866.

Riese, J., Yu, X., Munnerlyn, A., Eresh, S., Hsu, S.C., Grosschedl, R., and Bienz, M. 1997. LEF-1, a nuclear factor coordinating signaling inputs from wingless and decapentaplegic. Cell 88: 777-787.

Roose, J. and Clevers, H. 1999. TCF transcription factors: Molecular switches in carcinogenesis. Biochim. Biophys. Acta 1424: M23-M37.

Rothenberg, E.V. and Ward, S.B. 1996. A dynamic assembly of diverse transcription factors integrates activation and celltype information for interleukin 2 gene regulation. Proc. 
Nat1. Acad. Sci. 93: 9358-9365.

Rusch, J. and Levine, M. 1994. Regulation of the dorsal morphogen by the Toll and torso signaling pathways: A receptor tyrosine kinase selectively masks transcriptional repression. Genes \& Dev. 8: 1247-1257.

Schule, R., Muller, M., Otsuka-Murakami, H., and Renkawitz, R. 1988. Cooperativity of the glucocorticoid receptor and the CACCC-box binding factor. Nature 332: 87-90.

Singson, A. 1995. "Transcriptional activation by proneural proteins in Drosophila adult peripheral nervous system development." Ph.D. thesis, University of California San Diego, La Jolla.

Singson, A., Leviten, M.W., Bang, A.G., Hua, X.H., and Posakony, J.W. 1994. Direct downstream targets of proneural activators in the imaginal disc include genes involved in lateral inhibitory signaling. Genes \& Dev. 8: 2058-2071.

Small, S., Blair, A., and Levine, M. 1996. Regulation of two pair-rule stripes by a single enhancer in the Drosophila embryo. Dev. Biol. 175: 314-324.

Struhl, K. 1998. Histone acetylation and transcriptional regulatory mechanisms. Genes \& Dev. 12: 599-606.

- 2001. Gene regulation: A paradigm for precision. Science 293: 1054-1055.

Szuts, D., Eresh, S., and Bienz, M. 1998. Functional intertwining of Dpp and EGFR signaling during Drosophila endoderm induction. Genes \& Dev. 12: 2022-2035.

Tansey, W.P. 2001. Transcriptional activation: Risky business. Genes \& Dev. 15: 1045-1050.

Van Doren, M., Ellis, H.M., and Posakony, J.W. 1991. The Drosophila extramacrochaetae protein antagonizes sequencespecific DNA binding by daughterless/achaete-scute protein complexes. Development 113: 245-255.

Verschueren, K., Remacle, J.E., Collart, C., Kraft, H., Baker, B.S., Tylzanowski, P., Nelles, L., Wuytens, G., Su, M.T., Bodmer, R., et al. 1999. SIP1, a novel zinc finger/homeodomain repressor, interacts with Smad proteins and binds to $5^{\prime}$ CACCT sequences in candidate target genes. J. Biol. Chem. 274: 20489-20498.

Wang, S., Younger-Shepherd, S., Jan, L.Y., and Jan, Y.N. 1997. Only a subset of the binary cell fate decisions mediated by Numb/Notch signaling in Drosophila sensory organ lineage requires Suppressor of Hairless. Development 124: 44354446.

Xu, C., Kauffmann, R.C., Zhang, J., Kladny, S., and Carthew, R.W. 2000. Overlapping activators and repressors delimit transcriptional response to receptor tyrosine kinase signals in the Drosophila eye. Cell 103: 87-97.

Xu, X., Yin, Z., Hudson, J.B., Ferguson, E.L., and Frasch, M. 1998. Smad proteins act in combination with synergistic and antagonistic regulators to target Dpp responses to the Drosophila mesoderm. Genes \& Dev. 12: 2354-2370.

Yang, C., Shapiro, L.H., Rivera, M., Kumar, A., and Brindle, P.K. 1998. A role for CREB binding protein and p300 transcriptional coactivators in Ets-1 transactivation functions. Mol. Cell. Biol. 18: 2218-2229.

Zawel, L., Dai, J.L., Buckhaults, P., Zhou, S., Kinzler, K.W., Vogelstein, B., and Kern, S.E. 1998. Human Smad3 and Smad4 are sequence-specific transcription activators. Mol. Cell 1: 611-617.

Zenke, M., Grundstrom, T., Matthes, H., Wintzerith, M., Schatz, C., Wildeman, A., and Chambon, P. 1986. Multiple sequence motifs are involved in SV40 enhancer function. EMBO J. 5: 387-397.

Zhu, J., Gianni, M., Kopf, E., Honore, N., Chelbi-Alix, M., Koken, M., Quignon, F., Rochette-Egly, C., and de The, H. 1999. Retinoic acid induces proteasome-dependent degradation of retinoic acid receptor $\alpha(\mathrm{RAR} \alpha)$ and oncogenic RAR $\alpha$ fusion proteins. Proc. Natl. Acad. Sci. 96: 14807-14012. 


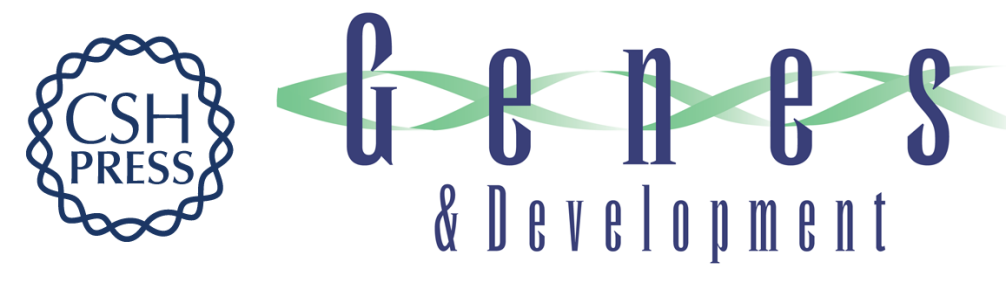

\section{Three habits of highly effective signaling pathways: principles of transcriptional control by developmental cell signaling}

Scott Barolo and James W. Posakony

Genes Dev. 2002, 16:

Access the most recent version at doi:10.1101/gad.976502

Related Content

References

This article cites 108 articles, 57 of which can be accessed free at:

\section{License}

Email Alerting Service http://genesdev.cshlp.org/content/16/10/1167.full.html\#ref-list-1

Articles cited in:

http://genesdev.cshlp.org/content/16/10/1167.full.html\#related-urls

\section{Rules for Development}

Sci. STKE May, 2002 2002: tw195

Receive free email alerts when new articles cite this article - sign up in the box at the top right corner of the article or click here.

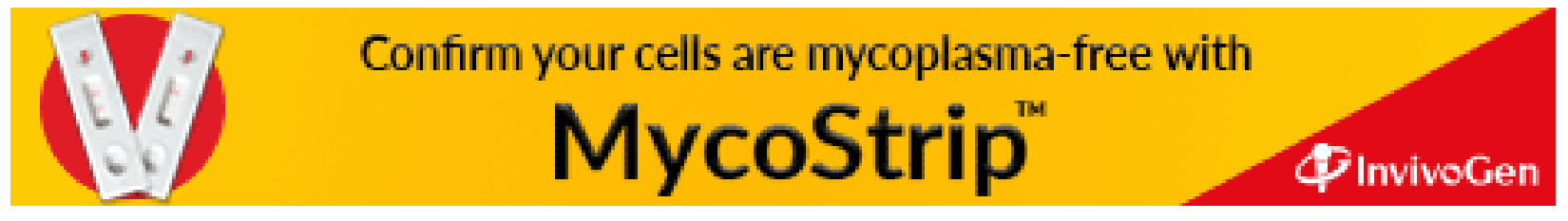

